\title{
Editorial for EAIT issue 3, 2020
}

\section{Arthur Tatnall ${ }^{1}$}

Published online: 1 May 2020

(C) Springer Science+Business Media, LLC, part of Springer Nature 2020

Education and Information Technologies (EAIT) is the official journal of the Technical Committee on Education (TC3) of the International Federation for Information Processing (IFIP). It covers the complex relationships between information and communication technologies and education, from the micro of specific applications or instances of use in classrooms to macro concerns of national policies and major projects; from classes of 5 year olds to adults in tertiary institutions; from teachers and administrators, to researchers and designers; from institutions to open, distance and lifelong learning. The journal's breadth of coverage allows EAIT to examine fundamental issues at all levels, discuss specific instances and cases, draw inference and probe theory. This journal is embedded in the research and practice of professionals.

The first article in this issue relates to flipped classrooms as Songül Karabatak and Hakan Polat (Firat University, Elazig, Turkey) present: The effects of the flipped classroom model designed according to the ARCS motivation strategies on the students' motivation and academic achievement levels. The study looks at the effects of the traditional classroom model, distance education model and flipped classroom model designed according to ARCS (attention, relevance, confidence and satisfaction) motivation strategies and academic achievement levels. Their results showed that the academic achievement levels of the students in the flipped classroom model using ARCS motivation strategies were significantly higher than those of the students in the distance education classroom and traditional classroom models.

Cândida Barros, Ana Amélia Carvalho and António Salgueiro (University of Coimbra, Portugal) then offer an article titled: The effect of the serious game Tempoly on learning arithmetic polynomial operations. They note that research on learning through serious games has gained importance in recent years. Their research involved developing the serious game Tempoly which was concerned with learning of the four arithmetic operations on polynomials. They conclude that the students liked playing the game and considered that it helped them learning the polynomial operations, and that what they learned in class was useful to play the game. The study revealed that the students that had more time to play the game did play more out of the class.

Arthur Tatnall

Arthur.Tatnall@vu.edu.au

1 Victoria University, Melbourne, Australia 
Successful transition to synchronous learning environments in distance education: A research on entry-level synchronous facilitator competencies to follow is from Amber Phelps (Bow Valley College, Calgary, Canada) and Dimitrios Vlachopoulos (Amsterdam University of Applied Sciences, The Netherlands). They begin by pointing out that synchronous education is being integrated at various levels and capacities in distance education. This offers learners and facilitators a virtual web-conferencing environment where they are able to be virtually present in a shared real-time space. The reported research aimed to reflect on what skills synchronous facilitators perceive as necessary for entry-level facilitators to demonstrate competence in to adequately support learners in the synchronous learning environment.

The next article notes that online learning is common in higher education, but has its drawbacks. An effective way of designing blended learning: A three phase designbased research approach contributed by Ahmet Berk Ustun (Bartin University, Turkey) and Monica Walch Tracey (Wayne State University, Detroit, USA) point out that blended learning (BL) has emerged as an alternative to alleviate the challenges of online learning. The design-based research study they carried out aimed to determine what elements were needed to assist a higher education lecturer who was inexperienced in designing and teaching a BL course to successfully create and implement one. They found that the design and implementation of BL led the lecturer to shift from a passive teaching approach to an active one, allowing the students to become active and interactive learners through the process of three iterative design cycles.

Roy Hanney and Gerda Skirkeviciutey (Solent University, Southampton, UK) next offer: Reflection, identity, community: Affordances of blogging for social interaction and reflective dialogue, showing findings from a study investigating implementation of course blogs on a media practice programme at a UK university. They note that literature on the use of course blogs suggests that blogging supports learning and promotes the attainment of skills in researching, academic writing, critical reflection and professional identity formation, but however there are difficulties for educators seeking to promote the use of course blogs as a productive and lively social practice. Their study of a group of L4 students sought to determine the barriers to developing blogging as a social practice and identify positive actions that will enhance the implementation of course blogging. Findings suggest that in the early stages of implementation one of the biggest challenge to developing blogging is resistance to change among staff. While among students the core theme is around ownership and motivation.

Natalia Vega, James Stanfield and Sugata Mitra (Newcastle University, UK) in their article: Investigating the impact of Computer Supported Collaborative Learning (CSCL) to help improve reading comprehension in low performing urban elementary schools, begin by noting that in the United States, literacy rates vary between socioeconomic groups, and this reading gap is also a common feature in the education systems of OECD member states. Teaching strategies that have a positive impact on student learning outcomes include use of peer collaboration and complex texts. Computer Supported Collaborative Learning to help address the reading gap for students attending low performing urban elementary schools has, to date, received much less attention and little is known about the ability of young students with access to the Internet to read complex texts in groups and how this impacts on individual reading comprehension scores. Their study examined the impact of combining the use of 
complex texts, collaborative learning and access to the internet on the reading comprehension scores of fourth-grade students.

In the modern, information driven society managing and handling data is unavoidable and Gábor Csapó, Mária Csernoch and Kálmán Abari (University of Debrecen, Hungary) address this in their article Sprego: case study on the effectiveness of teaching spreadsheet management with schema construction. They point out that the most common form of data handling is to organise it into tables and complete operations on them in spreadsheets. Sprego (Spreadsheet Lego) is a programming oriented methodology focusing on schemata construction and authentic problem solving working with only a limited number of general-purpose functions. The reported study presents Sprego as an alternative method for spread-sheeting, measuring its effectiveness in education compared to the traditional surface approach methods. They found that while traditional methods do not develop long-lasting knowledge which students could rely on and have a negative effect on their development, Sprego seems much more reliable.

In courses in 'English as a foreign language' traditional lecture-oriented teaching is still the norm, but with recent advances in technology an innovative teaching model has become popular across non-English-speaking subjects. The new model flips the usual classroom paradigm in which students learn primary concepts outside classroom and class time is reserved for more active problem-based learning. Flipped learning as situated practice: A contrastive narrative inquiry in an EFL classroom was contributed by Khadijeh Aghaei and Mojtaba Rajabi (Gonbad Kavous University, Iran), Koo Yew Lie (University of London, UK) and Fereshte Ajam (Islamic Azad University, Iran). This study employed a narrative inquiry, using data from interviews and observational field notes and the article describes what the researchers found.

Connecting to the digital age: using emergent technology to enhance student learning comes from Mohammed Alfadil (British University in Dubai, UAE), Derek Anderson (University of Northern Colorado, USA) and Amber Green (University of Northern Colorado, USA). The purpose of the reported study was to investigate student perceptions and experiences regarding emergent technology (such as laptops, tablets, and smartphones) used to achieve learning in a high school setting. The results revealed a significant difference between the perceptions of participants who used emergent technology in their classrooms as a tool to enhance learning and those who used emergent technology as a distraction.

Management of the Ghana Technology University College took the decision to adopt blended learning (BL) for teaching and learning because of its effectiveness as a learning approach. Ahmed Antwi-Boampong (Aalborg University, Denmark) reports on this in: Towards a faculty blended learning adoption model for higher education. As academics are apprehensive about teaching in a blended learning environment a major study to understand the factors influencing adoption of blended learning in the university has allowed a preliminary grounded theory model to be developed. This model identifies key factors, including pedagogy fitness, faculty technology affinity, student positive disposition to $\mathrm{BL}$ and institutional readiness that lead positively to motivate faculty to adopt BL.

Nabeel Al-Qirim (UAE University), Kamel Rouibah (Kuwait University), Mohamad Adel Serhani (UAE University), Ali Tarhini (Sultan Qaboos University, Muscat, Oman), Mahmoud Maqableh (The University of Jordan), Ashraf Khalil 
(Abu Dhabi University, UAE) and Marton Gergely (UAE University) next offer: Antecedents to academic success in higher education institutions: The case of $\boldsymbol{U A E}$ University. Their research goal was to develop a model to investigate the influence of different determinants on student's Academic Performance in UAE University. Their model consists of Big Five personality traits (BigF) and other learningorientation strategies, and their research offered interesting insights to the university's student's learning strategies, traits and habits.

An immersive virtual reality educational intervention on people with autism spectrum disorders (ASD) for the development of communication skills and problem solving was presented by Jorge Fernández Herrero and Gonzalo Lorenzo (University of Alicante, Spain). Their paper proposes the design and application of a head-mounted display immersive virtual reality system to improve and train the emotional and social skills of students with autism spectrum disorders. In their research they investigated two groups (one as a control) of high functioning ASD children (8 to 15) with similar educational capabilities. They used an intervention design working on social and emotional competences along with using Immersive Virtual Reality (IVR) as a didactical tool, recreating virtual environments of socialization (a classroom and a play garden). They found that adaptation levels and improvements obtained in the presented format with IVR are in line with the sensory preferences and visuospatial strength of the ASD children participating in this study.

To follow, Kingsley Ofosu-Ampong (University of Ghana Business School), Richard Boateng (University of Ghana Business School), Thomas Anning-Dorson (University of Ghana Business School and Wits Business School, South Africa) and Emmanuel A. Kolog (University of Ghana Business School) then write on: Are we ready for Gamification? An exploratory analysis in a developing country. They claim that integrating gamification in the learning process has become a significant factor in the success of teaching, learning, and research in higher education and that education can leverage gamification by enhancing learning management systems to make learning enjoyable and engaging for students. In their research they explored the users' perception and acceptance of adding gamification to learning in higher education. Their results showed that Image is an insignificant factor in students' behavioral intention to use gamification.

Teenagers connected to digital environments - what happens when they get to school? Commonalities, similarities and differences from their perspective follows. Gila Cohen Zilka (Bar-Ilan University, Israel) presents a study examining teenagers' perspectives of how the digital environment is integrated into their school life. The findings showed that what teenagers have in common is extensive use of their smartphones and computers for study-related matters. They use many apps and social networks and belong to a variety of study-related groups to obtain relevant information to solve problems or to satisfy their curiosity. A difference, however, lies in their comparison of the digital environments of their smartphone and home computer and those used in school. Some participants found the school environment outdated, slow, and scholastically and technologically unchallenging.

As information technology continues to evolve rapidly in society, coding skills become increasingly essential to develop. Learning by coding: A sociocultural approach to teaching web development in higher education by Montathar Faraon (Kristianstad University, Sweden), Kari Rönkkö (Kristianstad University, 
Sweden), Mikael Wiberg (Umeå University, Sweden) and Robert Ramberg (Stockholm University, Sweden) addresses this topic. They examine differences between the learner-centred and sociocultural approaches when teaching and learning coding in higher education in terms of students' explicit attitudes, grades and course evaluations. They found that the sociocultural may be a viable alternative to the learner-centred approach, but that its integration must be carefully balanced against constraints, such as time and resources that teachers continuously experience in higher education.

The next article: Matching self-reports with electrodermal activity data: Investigating temporal changes in self-regulated learning comes from Muhterem Dindar (University of Oulu, Finland), Jonna Malmberg (University of Oulu, Finland), Sanna Järvelä (University of Oulu, Finland), Eetu Haataja (University of Oulu, Finland) and Paul A. Kirschner (Open University of the Netherlands). Their study investigated the interplay of temporal changes in self-regulated learning processes (behavioural, cognitive, motivational and emotional) and their relationship with academic achievement in computer-supported collaborative learning. The study employed electrodermal activity and self-report data to capture the dynamicity of self-regulated learning. They found that change in motivational regulation was related to academic achievement, but that academic achievement was not related to behavioural regulation, cognitive regulation or emotional regulation.

Gamification in management education - A literature mapping is from Rui Silva (University of Trás-os-Montes e Alto Douro, Portugal), Ricardo Rodrigues (University of Beira Interior, Portugal) and Carmem Leal (University of Trás-os-Montes e Alto Douro, Portugal). They note that application of gamification to the teaching-learning process across different fields of knowledge constitutes an emerging practice applied across all levels of education from primary school up to university. The article presents a mapping of research articles that approach the application of gamification techniques to teaching-learning processes in general education of all areas and the teaching of management in particular. In order to achieve this, the article describes the organisational structure of the field research in terms of publications, authors and journals as well as identifying and classifying the research articles about adopting gamification methods.

Healthy Jeart is a free app targeted to young people and designed to foster a healthy lifestyle. The article that follows: Healthy Jeart. Developing an app to promote health among young people was written by Ana Duarte-Hueros (University of Huelva, Spain), Carmen Yot-Domínguez (University of Seville, Spain) and Ángeles Merino-Godoy (University of Huelva, Spain). Young people can find in Healthy Jeart practical recommendations about seven areas of health and a game through which they can consolidate the acquired knowledge on different healthy and beneficial elements, and it is also useful for healthcare professionals and educators. The article describes its design, production, revision and evaluation process.

Designing a professional development program for mathematics teachers for effective use of technology in teaching from Seyum Tekeher Getenet (University of Southern Queensland, Australia) demonstrates the importance and procedures of learners and learning context analysis to design a context-driven professional development program to effectively use technology in mathematics classrooms. The study 
showed that analyses of the learning context and teacher educators' context were essential to design a context-driven professional development program containing relevant examples, contents, and scenarios for teachers.

The next article, from Kazakhstan looks at teaching mobile application development and, as a consequence, training of highly qualified in-demand mobile developers which is a crucial task all over the world. A spiral model teaching mobile application development in terms of the continuity principle in school and university education comes from G. Aimicheva and Zh. Kopeyev (L.N. Gumilyov Eurasian National University, Kazakhstan) Zh. Ordabayeva (Pavlodar State University, Kazakhstan), N. Tokzhigitova (Pavlodar State University, Kazakhstan) and S. Akimova (M.Utemisov West-Kazakhstan State University, Kazakhstan). The researchers emphasize the complexity of mobile application development associated with its multi-disciplinarity, the mobile device hardware limitations, and the necessity of object-oriented programming in mobile development. They propose a spiral model that covers all levels of teaching programming from high school to higher education with the aim of developing knowledge from introductory programming to mobile application development. This model suggests continuity in the content and overcoming the gap in programming knowledge between high school and higher education.

Michael Glassman (The Ohio State University, USA) next offers: The internet as a context for participatory action research, suggesting that formal education must take new approaches to meet the social opportunities and challenges brought about through the information revolution, particularly access to new information, capabilities for new types of communities that can challenge place-based agendas, and distributed power and voice. The author claims that the tools of the Internet are unique as they offer new types of individual agency capable of ameliorating injustice and oppression that thrives in the shadows, but also leading to unprecedented social dangers. Especially for the marginalized and oppressed these offer possibilities to join together as a community and common voice. Participatory Action research is proposed as one possible framework to formal education that meets these uniquely twenty-first century needs.

Predicting student final performance using artificial neural networks in online learning environments by Șeyhmus Aydoğdu (Nevșehir Hacı Bektaș Veli University, Turkey) suggests the importance of prediction of student performance using educational data mining. Artificial neural networks are seen to be an effective tool in predicting student performance in e-learning environments. In the reported study, artificial neural networks were used to predict the performance of university students who studied and participated in a learning management system in relation to gender, content score, time spent on the content, number of entries to content, homework score, number of attendances to live sessions, total time spent in live sessions, number of attendances to archived courses and total time spent in archived courses variables. The artificial neural network created as a result of the study makes a prediction with an accuracy of about $80 \%$.

The next article reports on a study that examined Indonesian pre-service language teachers' use of information and communication technology (UICT) during teaching practices. The role of TPACK in affecting pre-service language teachers' ICT integration during teaching practices: Indonesian context from Akhmad Habibi (University of Malaya/ LPDP Indonesia, Malaysia), Farrah Dina Yusop (University of Malaya, Malaysia) and Rafiza Abdul Razak (University of Malaya, Malaysia) 
reports on the use of the technological pedagogical and content knowledge (TPACK) framework to predict the UICT and so determine if the TPACK is a valid model to explain Indonesian pre-service language teachers' UICT during teaching practices. Overall, the TPACK components reported to be a valid model to help explain Indonesian pre-service language teachers' UICT during teaching practices.

Predictive analytics in education: a comparison of deep learning frameworks by Tenzin Doleck (University of Southern California, USA), David John Lemay (McGill University, Montreal, Canada), Ram B. Basnet (Colorado Mesa University, USA) and Paul Bazelais (McGill University, Montreal, Canada) points out that large amounts of data are readily available in various fields, and education is no exception. Recent advances in deep learning, particularly in the area of voice and image recognition and so-called complete knowledge games like chess, go, and StarCraft, have resulted in a flurry of research. Their research involved using two educational datasets to explore the utility and applicability of deep learning for educational data mining and learning analytics and so compare the predictive accuracy of popular deep learning frameworks/ libraries, including, Keras, Theano, Tensorflow, fast.ai, and Pytorch. They found that deep learning displays comparable performance to other machine learning algorithms such as support vector machines, k-nearest neighbours, naive Bayes classifier, and logistic regression.

The article that follows: Virtual educational environment: interactive communication using LMS Moodle considers the problems relating to vocational training of specialists in the virtual educational environment of a higher education institution. It was contributed by Nurassyl Kerimbayev and Nurdaulet Nurym (al-Farabi Kazakh National University, Kazakhstan), Aliya Akramova (Almaty University, Kazakhstan) and Saule Abdykarimova (Asfendiyarov Kazakh National Medical University, Kazakhstan). The article presents the experience on introduction of a virtual educational environment using LMS Moodle where the researchers considered the influence of this environment on the interactive engagement of students and teachers from the universities in Kazakhstan and Slovakia. They demonstrate how the LMS Moodle platform helps arrange e-learning, conduct lessons in electronic classrooms, take online courses, and conduct synchronous and asynchronous learning.

Exploring the effect of knowledge acquisition and knowledge sharing on e-learning adoption is a relatively new research trend that has not been featured in the existing literature. The reported study, by Mostafa Al-Emran (Ton Duc Thang University, Vietnam) and Timothy Teo (Murdoch University, Australia), was conducted to build a new model by extending the technology acceptance model (TAM) with knowledge acquisition and knowledge sharing to examine e-learning adoption. Their article: Do knowledge acquisition and knowledge sharing really affect e-learning adoption? An empirical study reports on research using the Partial Least Squares-Structural Equation Modeling (PLS-SEM) to evaluate the proposed model. The results suggested that knowledge acquisition, knowledge sharing, perceived usefulness, and perceived ease of use have significant direct effects on the students' behavioural intention to adopt elearning systems. Implications for theory and practice, limitations, and future work are also discussed.

The effectiveness of animated video and written text resources for learning microeconomics: A laboratory experiment by Alice Shiu and Joseph Chow (The Hong Kong Polytechnic University) and Judith Watson (University of New South 
Wales, Australia) notes that students' diverse learning modes create a need to develop various learning materials for effective learning, and suggest animated videos to complement classroom teaching. Their study describes the design of learning materials and a laboratory experiment which randomly assigned business and non-business students to either a video or a text group to collect students' perception. The analysis showed that students perceived both types of materials as comparable and regarded both positively, suggesting that video is an effective alternative to text materials.

The next article, by Kübra Açıkgül and Recep Aslaner (Inonu University, Turkey), describes a study to investigate the effects of GeoGebra Supported Micro Teaching Applications and TPACK Game Practices on the TPACK efficacy and self-efficacy perception levels of the prospective math teachers on polygons. Effects of Geogebra supported micro teaching applications and technological pedagogical content knowledge (TPACK) game practices on the TPACK levels of prospective teachers details how prospective teachers were separated into four groups, one participating in Micro Teaching Applications and Game- Based TPACK Activities, one in GeoGebra Supported Micro Teaching Applications, one in Micro Teaching Applications and GeoGebra Supported Micro Teaching Applications and one in Game-Based TPACK Activities. It was determined all application processes increased prospective teachers' TPACK efficacy and self-efficacy scores.

Dealing with conflict in learning teams immersed in technology-rich environments: A mixed-methods study by Ana-Paula Correia (The Ohio State University, USA) proposes that understanding the nature of conflict and the role that it plays in the dynamics of teamwork has the potential to improve group processes and make teams more successful. The reported research, involving how learning teams of graduate students enrolled in a team-based, graduate-level course, showed that perceptions of conflict evolve over time, moving from less favourable views to more constructive ones. Teams used different modes of conflict management throughout the study, generally evolving from less cooperative to more integrative forms of conflict management which supported collaborative learning. Students who were less proficient in the use of technology generally perceived conflict as having negative effects on the project's outcomes, while proficient users tended to perceive conflict as having a positive influence on their teamwork.

In the next article: Between text and platforms: A case study on the real-time emotions \& psychophysiological indicators of video gaming and academic engagement Matthew Moreno, Rose Schnabel, Gabriella Lancia and Earl Woodruff (University of Toronto, Canada) point out that literature indicates that both academic tasks and video gaming have qualities that engage and captivate individuals. The reported case study gives the findings of a new method for simultaneously capturing the emotional, psychophysiological response and personal experiences of one expert video-gamer and one expert writer. After completing a thematic analysis of each expert's activity, findings indicated both experienced a flow-like state that coincided with increased facio-emotional values of confusion, decreased GSR, and increased EEG brain activity (Beta and Gamma), providing indicators of engagement.

The UAE Ministry of Education strives to use modern technological and educational methods to teach students in higher education institutions and to assure high-quality education say Sami Al-Qatawneh, Mohd. Elmagzoub Eltahir and Najeh Rajeh Alsalhi (Ajman University, UAE) in their article: The effect of blended learning on the 
achievement of HDE students in the methods of teaching Arabic language course and their attitudes towards its use at Ajman University: A case study. Their study aimed to investigate the effects of blended learning on the achievements of students in a higher diploma in education course at the university that compares the results of different ways of teaching the 'Methods of Teaching the Arabic Language course', and students' attitudes towards their use. The findings showed that students of the experimental group have positive attitudes towards the using of blended learning.

Mobile learning under personal cloud with a virtualization framework for outcome based education comes from Susanta Mitra and Somsubhra Gupta (Amity University, India). They note that mobile learning under a cloud environment, an amalgamation between mobile cloud computing and mobile learning has gained wide academic and commercial recognition during the last few years. This is expected to make learning more cost-effective, collaborative and practical for the learners using a Personal Cloud environment. The work expedites the proposed virtualization framework and how it provides a technical backbone in which some pedagogical reforms may optimise knowledge transfer substantiating outcome based education and be of benefit to mass learners including poor and under privileged, so helping to reduce the digital divide.

Noor Al-Qaysi (Universiti Pendidikan Sultan Idris, Malaysia), Norhisham Mohamad-Nordin (Universiti Pendidikan Sultan Idris, Malaysia and University of Nizwa, Oman) and Mostafa Al-Emran (Ton Duc Thang University, Vietnam) next write on: What leads to social learning? Students' attitudes towards using social media applications in Omani higher education. Social learning refers to learning delivered through social media applications, but students' attitudes towards this for learning activities is still not fully understood. The reported research was carried out with the aim of measuring students' attitudes towards using social media from the lenses of several attributes, including gender, age, governorate, year of study, social media application, experience, and interest. The results showed that gender, age, governorate, experience, and interest have significant impacts on students' attitudes, but that study years and social media applications did not have any significant effect.

In recent years, there has been a renewed interest in the introduction of programming in teacher education and professional development, highlighting its importance for the development of so-called computational thinking and Natalia Monjelat (National Scieentific and Technical Research Council (CONICET), Argentina) and Annika Lantz-Andersson (University of Gothenburg, Sweden) address this in: Teachers' narrative of learning to program in a professional development effort and the relation to the rhetoric of computational thinking. Their study explored primary education teachers' participation in programming practices. By focusing on their views of creating a computational artefact with Scratch, the difficulties encountered, and resources to overcome them in the context of a professional development effort in computer science at the primary education level, was analysed. Findings revealed that projects that had educational content involved more elaborate descriptions, while recreational projects presented a shorter and less elaborate account of the programming process.

Predictors of cyberloafing among high school students: unauthorized access to school network, metacognitive awareness and smartphone addiction was contributed by Mustafa Saritepeci (Necmettin Erbakan University, Turkey). The researcher notes 
that cyberloafing is a phenomenon that adversely affects efficiency and productivity in learning and teaching and that increased ICT access in educational environments and personal mobile devices leads to a wide range of cyberloafing behaviours of learners. The aim of the reported study was to investigate cyberloafing behaviors of high school students in terms of several variables, including gender, ICT usage, unauthorized access to school network, metacognitive awareness and smartphone addiction. It was concluded that unauthorized access to the school network of learners has a significant impact on the cyberloafing behaviours and that smartphone addiction and metacognitive awareness levels of students, as well as daily social media usage time are fundamental predictors of cyberloafing behaviours.

Context aware mobile learning application development: A systematic literature review is by Bimal Aklesh Kumar (Fiji National University) and Bibhya Sharma (University of the South Pacific, Fiji). Context Aware Mobile Learning Applications (CAMLA) provide educational resources tailored to the needs and particular circumstances of the learner and are an emerging field of research. A systematic literature review was conducted to establish a body of knowledge that describes the key components of CAMLA. These include: context information extraction and representation, context adaptation and different types of applications developed.

Rosa Bottino (Italian National Research Council - Institute of Educational Technology, Italy) next writes on: Schools and the digital challenge: Evolution and perspectives in which she proposes a reflection on the evolution of educational technologies and its impact on school education. Over time, even though with different approaches, methods and tools, educational technology as a field of research has followed substantially two main directions. The first has resulted in studies on new technical and conceptual skills required by digital technologies, the second has focused on use of ICT to change teaching and learning environments and the way in which curricular subjects are taught. In the paper the evolution of research in educational technology is briefly outlined considering these two orientations and also of how policy issues influence the large-scale implementation of plans for digital schools with a brief examination of the specific case of Italy.

Previous research has produced contrasting findings regarding the influence of social networking on academic performance, some finding negative relationships and others positive. Patterns of social networking use and academic performance: Examining the link between quality and frequency of social networking use and academic performance among college-level students by David John Lemay and Paul Bazelais (McGill University, Montreal, Canada) and Tenzin Doleck (University of Southern California, USA) addresses this. They examine the relationship between frequency, duration, and problematic (i.e. maladaptive) use of social networking sites (SNS) on perceived performance expectancy and actual academic performance of a sample of college-level students recruited at a pre-university program in Northeastern Canada. Their findings suggest that different measures of SNS use and academic performance can yield different links between social networking and academic performance.

The next article: Parental mediation of young children's internet use: Adaptation of parental mediation scale and review of parental mediation based on the demographic variables and digital data security awareness describes research by Aykut Durak and Hüseyin Kaygin (Bartin University, Turkey). Their work involved adapting 
'Parental Mediation of Young Children's Internet Use Scale'- which was developed by Nikken and Jansz into Turkish. The study was conducted in two steps. Firstly, data was collected for the scale adaptation process, and validity and reliability of the scale were calculated. Next, scanning was done through the adaptive scale. Within the frame of this study, parental mediation of their young children's internet use levels were found to differentiate based on levels of age, education and internet usage experience through the scanning done by utilizing the scale created as a result of the scale adaptation. Additionally, a positive and meaningful relation between parental mediation scores and digital data security was found.

The final article in this issue is: Exploratory analysis of factors influencing $e$ learning adoption by higher education teachers Case study: Abdelmalek Essaâdi University-Morocco. It comes from Bouyzem Meriem and Meriouh Youssef (Ecole Nationale de Commerce et de Gestion Tangier, Morocco). They note that e-learning has become an increasingly popular form of training throughout the world for both students and teachers and several Moroccan universities have launched e-learning courses. Abdelmalek Essaâdi University is involved in a project called 'MarMooc' funded by the European Union and aimed at the production of MOOC and SPOC at the national level. In this article they present a survey conducted by questionnaire with both open and closed questions in order to study factors influencing e-learning adoption by higher education's teachers in Morocco, especially Abdelmalek Essaâdi University's teachers. Analysis of responses to open-ended questions, of correlations and principal component analysis revealed following factors: institutional factors, teacher-related factors and Students' factors.

Articles in this issue come from researchers in: Turkey, Portugal, Canada, The Netherlands, USA, UK, Hungary, Iran, UAE, Denmark, Kuwait, Oman, Spain, Ghana, South Africa, Israel, Sweden, Finland, Australia, Kazakhstan, Malaysia, Vietnam, Hong Kong, India, Argentina, Fiji, Italy and Morocco.

\section{Arthur Tatnall}

Editor-in-Chief

Publisher's note Springer Nature remains neutral with regard to jurisdictional claims in published maps and institutional affiliations. 